\title{
Unusual etiology of gastrointestinal symptoms: the case of jojoba butter
}

\author{
This article was published in the following Dove Press journal: \\ Open Access Emergency Medicine \\ 7 February 2017 \\ Number of times this article has been viewed
}

\author{
Michael R Minckler \\ Joseph Fisher ${ }^{2}$ \\ Rachel Bowers ${ }^{2}$ \\ Richard Amini' \\ 'Department of Emergency Medicine, \\ University of Arizona, ${ }^{2}$ College of \\ Medicine, University of Arizona, \\ Tucson, AZ, USA
}

Background: Jojoba butter is cyanogenic and has gained attention among herbal supplement consumers due to claims that it may aid in weight loss. Jojoba butter is extracted from the seeds of jojoba shrubs found in the Sonoran Desert. The seeds have long been recognized as inedible, however clinical symptoms following ingestion are not well documented.

Case report: This report describes a patient who developed restlessness and gastrointestinal complaints following ingestion of homemade jojoba seed butter. The patient's presentation following ingestion is discussed, as well as effective workup and treatment. In our case, the patient was monitored and received fluid resuscitation, lorazepam, and diphenhydramine for symptomatic therapy.

Conclusion: This case describes the gastrointestinal sequela and effective management following ingestion of jojoba butter.

Keywords: jojoba butter, simmondsin, cyanoglycoside, anorectic

\section{Introduction}

The use of herbal and dietary supplements continues to grow in popularity as individuals seek alternative methods to aid in weight loss and dieting. Although there is lack of sufficient research regarding the safety and efficacy of numerous supplements, consumers often believe that these products are harmless because they are "natural". ${ }^{1}$ Jojoba (Simmondsia chinenesis) has recently gained recognition among herbal supplement consumers due to claims that it may aid in weight loss. Simmondsin, a cyanoglycoside found in the meal extracted from jojoba seeds, has been shown to be toxic in animal studies. ${ }^{2}$ However, a toxidrome following ingestion of jojoba seeds has not been previously described in humans.

\section{Case presentation}

A 62-year-old man presented to the emergency department complaining of worsening diarrhea, body aches, restlessness, dry eyes, and thirst that began immediately after consuming homemade jojoba seed butter. The patient had handpicked jojoba seeds from local shrubs and, with a clean grain mill, used them to make butter. He then consumed 5 tablespoons of the freshly made butter in a single sitting at 1700 and denied any coingestion. He claims to have made and used jojoba butter in the past, but never consumed this large a quantity in such a short period of time. He reported
Correspondence: Joseph Fisher College of Medicine, University of Arizona, 5626 East 6th Street Tucson, AZ 857II, USA

E-mail jhfisher@email.arizona.edu 
experiencing symptoms immediately after ingesting the seed butter. His condition gradually worsened over the course of the evening, and he was triaged in our emergency department at 0600 , the following morning.

At presentation, he appeared anxious but was alert and oriented. He was tachypneic, breathing 24 respirations per minute; otherwise he was afebrile and all other vitals were within reference range. During interview, he reported being in his usual state of good health until he consumed the jojoba seed butter. He denied any associated pain, emesis, vision changes, auditory or visual hallucinations, suicidal or homicidal ideation, or any symptoms prior to ingestion. The patient denied any past medical problems, and he did not take any prescription medications or over the counter supplements. On examination, the patient was found to be diaphoretic and tremulous with dry mucous membranes. Neurologic, cardiovascular, and abdominal examinations were otherwise non-remarkable.

Laboratory work consisting of a venous blood gas, complete blood count, lactate, creatine kinase, lipase, comprehensive metabolic panel, and thyroid stimulating hormone were all within normal limits. The patient's electrocardiogram showed no evidence of ischemia or arrhythmia. He was treated symptomatically with a bolus of normal saline, lorazepam, and diphenhydramine. He was observed in the emergency department and discharged later that day after his symptoms resolved.

\section{Conclusions}

Jojoba seed butter or jojoba meal is produced by extraction of the oil and retention of the seed meal, and it is generally designed for cosmetic purposes. ${ }^{3,4}$ The extracted meal has held limited utility because it has long been recognized to contain anti-nutritional constituents, ${ }^{5}$ including the cyanoglycoside simmondsin which has been shown to be toxic in various animal studies. ${ }^{2,5}$ It has been postulated that the toxic effects of jojoba meal may be related to the formation of cyanide in an unknown digestive process. Although this theory cannot be excluded, the formation of cyanide as a by-product of digestion has yet to be demonstrated in animal studies $^{6}$ and the adverse effects of simmondsin are largely believed to be related to its anorectic effects. ${ }^{6-7}$

Although the anorexic mechanism of the glycoside action is not fully understood, studies have shown that there appears to be indirect action on cholecystokinin (CCK) receptors. ${ }^{6,8,9}$ $\mathrm{CCK}$ has paracrine action on vagal afferent fibers from the gastrointestinal tract leading to gastric acid secretion, pancreatic enzyme stimulation, and decreased gastric motility, as well as various systemic effects. ${ }^{10} \mathrm{~A}$ previous case report regarding a patient with a CCK-releasing neuroendocrine tumor described a symptomology of diarrhea, severe weight loss, gallstones, and peptic ulcer disease. ${ }^{11}$ Oral CCK agonists have been studied on human subjects, and reported side effects have included diarrhea, nausea, emesis, and headaches. ${ }^{10}$

While jojoba meal has largely been ignored as an edible food, it has recently gained attention because of its appetite suppressing effects. Simmondsin can be found as an active ingredient in a multitude of weight loss supplements that have not received acknowledgment from the US Food and Drug Administration, and simmondsin holds various weight loss patents. Since it is often sold as a supplement, there is very little regulation of the purity or quantity of simmondsin within products claiming to contain the extract. Furthermore, home extraction and preparation of the meal is riddled with imperfections, including discrepancies in simmondsin quantity based on geographic location and extraction methodology. ${ }^{12}$ Simmondsin intoxication may have a subtle presentation. A high index of suspicion based on clinical history and a strong understanding of similar toxic syndromes are often the best devices in an emergency medicine physician's toolbox.

\section{Consent}

The patient discussed in this case report provided written consent for this report to be published.

\section{Disclosure}

The authors report no conflicts of interest in this work.

\section{References}

1. Stickel F, Shouval D. Hepatotoxicity of herbal and dietary supplements: an update. Arch Toxicol. 2015;89(6):851-865.

2. Lievens S, Verbaeys I, Flo G, Briers R, Decuypere E, Cokelaere M. Disruption of the behavioral satiety sequence by simmondsin. Appetite. 2009;52(3):703-710.

3. Bouali A, Bellirou A, Boukhatem N, Hamal A, Bouammali B. Enzymatic detoxification of jojoba meal and effect of the resulting meal on food intake in rats. Nat Prod Res. 2008;22(7):638-647.

4. Cokelaere M, Daenens P, Decuypere E, et al. Reproductive performance of rats treated with defatted jojoba meal or simmondsin before or during gestation. Food Chem Toxicol. 1998;36(1):13-19.

5. Brimer L. Chemical Food Safety. CABI; First edition (June 28, 2011).

6. Cokelaere MM, Busselen P, Flo G, et al. Devazepide reverses the anorexic effect of simmondsin in the rat. $J$ Endocrinol. 1995;147(3):473-477.

7. Boozer CN, Herron AJ. Simmondsin for weight loss in rats. Int J Obes (Lond). 2006;30(7):1143-1148.

8. Flo G, Van Boven M, Vermaut S, Daenens P, Decuypere E, Cokelaere M. The vagus nerve is involved in the anorexigenic effect of simmondsin in the rat. Appetite. 2000;34(2):147-151. 
9. Flo G, Vermaut S, Van Boven M, et al. Comparison of the effects of simmondsin and cholecystokinin on metabolism, brown adipose tissue and the pancreas in food-restricted rats. Horm Metab Res. 1998;30(8):504-508.

10. Castillo EJ, Delgado-Aros S, Camilleri M, et al. Effect of oral CCK-1 agonist GI181771X on fasting and postprandial gastric functions in healthy volunteers. Am J Physiol Gastrointest Liver Physiol. 2004;287(2): G363-369.
11. Rehfeld JF, Federspiel B, Bardram L. A neuroendocrine tumor syndrome from cholecystokinin secretion. $N$ Engl J Med. 2013;368(12) 1165-1166.

12. Benzioni A, Mills D, Van Boven M, Cokelaere M. Effect of genotype and environment on the concentration of simmondsin and its derivatives in jojoba seeds and foliage. Industrial Crops and Products $2005 ; 21(2): 241-249$.

\section{Publish your work in this journal}

The Open Access Emergency Medicine is an international, peerreviewed, open access journal publishing original research, reports, editorials, reviews and commentaries on all aspects of emergency medicine. The manuscript management system is completely online and includes a very quick and fair peer-review system, which is all

\section{Dovepress}

easy to use. Visit http://www.dovepress.com/testimonials.php to read real quotes from published authors. 